\title{
Research on the Topic Selection of the Graduation Project for the Architecture Major
}

\author{
Xiaohong Ding \\ Faculty of Architecture and Civil Engineering of Huaiyin Institute of Technology, Huai'an, China \\ Email: dingxiaohong7725@126.com
}

How to cite this paper: Ding, X. H. (2020). Research on the Topic Selection of the Graduation Project for the Architecture Major. Open Journal of Social Sciences, 8 , 279-285.

https://doi.org/10.4236/jss.2020.812022

Received: November 22, 2020

Accepted: December 19, 2020

Published: December 22, 2020

Copyright (c) 2020 by author(s) and Scientific Research Publishing Inc. This work is licensed under the Creative Commons Attribution International License (CC BY 4.0).

http://creativecommons.org/licenses/by/4.0/

(c) (i) Open Access

\begin{abstract}
Based on the comprehensive analysis of the reasons for the problems in the topic selection of the graduation project for the architecture major, such as the degree of difficulty which does not fully meet the teaching goals, singleness, lack of truthfulness, and inconsistency in students' interest, this article proposes that the topic selection of the graduation project for the architecture major should fully consider factors such as scientificity, diversity, authenticity and adaptability; the topic selection should be moderate in size and difficulty, and scientific topic selection suggestions such as "real questions and fake answers" and flexible topic selection based on students' specific circumstances are advocated, so as to achieve the goal of improving the quality of architectural graduation project in ordinary colleges and universities.
\end{abstract}

\section{Keywords}

Architecture, Graduation Project, Topic Selection

\section{Introduction}

In recent years, with the continuous expansion of the enrollment scale of ordinary colleges and universities, there have been more and more architecture students and a large number of graduates enter the market every year. At the same time, the number of recruits in design units is limited. What's more, some large design companies have high requirements for new recruits. Not only must they have high overall quality, they must also be quick to start working, and they are required to directly participate in the design of the company's engineering projects after graduation. The contradiction between the supply and demand of talent training has promoted the cultivation of the ability of architecture students in colleges and universities to a new height and accelerated the reform of professional teaching (Zhang \& Song, 2011). 
The graduation project is the last practice teaching session for architecture students in the school for five years. It is not only a sign of the end of architecture main courses, but also an important transition for students from school to social work. The teaching of graduation project is of great significance to improving the quality of undergraduate teaching and enhancing the social adaptability of students through the training of students' engineering design, scientific research thinking and design methods.

Graduation project for the architecture major can generally be divided into three stages (Su, Liu, \& Pan, 2011): topic selection, project design, and outcome defense; among them, scientific topic selection is the key link of the graduation project for the architecture major. The primary task of the graduation project for the architecture major is to determine the project topic. The source, scale and final result requirements of the topic directly affect the quality of the final graduation project for students. How to choose a graduation project topic that can not only meet the requirements of the teaching objectives, but also allow students to exercise all aspects of their knowledge is a question worthy of serious consideration for every graduation project instructor in the architecture major before the graduation project.

Graduation project is the last teaching link of students' study in school, and its topic selection is the primary factor that determines the quality of graduation project. We must combine the market demand and strive for the scientificity, diversity, authenticity, adaptability, feasibility and uniqueness (Du, Zhang, \& Cheng, 2011) of the topic selection according to the requirements of the outline, so as to lay a good foundation for students to get systematic training and improve their ability in the graduation project.

\section{Main Problems in the Topic Selection of the Architectural Graduation Project}

\subsection{The Difficulty of the Topic Selection Does Not Fully Meet the Teaching Objectives}

Whether the graduation project for the architecture major can achieve the teaching objectives first of all lies in the determination of the project topics. In actual teaching, some topics cannot fully meet the professional teaching objectives, and there may even be questions that are too big or too small. For example, some topics are the planning and design of campus buildings or general hospitals with more than 100,000 square meters. The design is too difficult or the workload is too large. It is very difficult for students to design, and the final results are not satisfactory. Some questions are too small in scale, with only a few thousand square meters of low-rise or multi-storey buildings, and some of them do not even meet the depth requirements of the graduation project. Students can easily complete them, and they cannot detect the true level of the students, let alone reach the quality requirements that the undergraduate architectural graduation project should meet (Gui \& Wu, 2020). 


\subsection{The Topic Selection Is Relatively Single and Dated}

Based on the graduation project topics of the architecture major of our school in recent years, most of the topics are mainly focused on the design of single buildings (such as museums, hospital ward buildings and activity centers), and the project topics are relatively single and fail to meet the requirements of diversified teaching. Some teachers have used the same topics for many years when selecting topics for their graduation projects, with the purpose of completing the teaching tasks instead of being driven by factors such as student interests, employment trends, and the training goals of applied undergraduate colleges. This is bound to cause the topics to be obsolete and unable to reflect the forefront of the development of enterprises in the industry, thus unable to ensure the quality of graduation project (Liang, Xuan, \& Li, 2009).

\subsection{The Topic Selection Is Not True Enough}

In recent years, some teachers in our school have chosen completely "fake questions and fake answers", without clear engineering background, practical significance, real location, geographical or climate requirements, and some do not even have topographic maps, which are completely meaningless. Students are not interested in such topics, and they are out of touch with actual work after graduation, which is not conducive to students' future work.

\subsection{The Topic Selection Does Not Match the Students' Interests}

The current practice of our school's architecture major is that the teacher first selects the topic, and then the students choose the topic according to their own preferences; but in fact, some students choose the topic without looking at the topic, but choose the teacher with a good relationship or the teacher who is affable first, and then choose the topic. The topics chosen are often inconsistent with the students' interest and employment direction. It is difficult to achieve the expected effect of the graduation project, and the quality of the graduation project cannot be effectively guaranteed.

\section{Suggestions on Selecting Topics of the Graduation Project for the Architecture Major Scientifically}

\subsection{The Comprehensiveness and Innovation of the Topic Selection}

The graduation project is different from the usual course design, and its focus is to comprehensively examine the comprehensive ability of students. The graduation project should be combined with the practical tasks of production and scientific research as much as possible to promote the organic combination of teaching, scientific research and practice (Nie, 2008). However, since each graduation project instructor has its own expertise and research direction, there may be big differences in scale, difficulty, and type of construction in the topic selection. Therefore, schools should formulate reasonable topic selection standards and scientific and standardized teaching objectives, and have more detailed re- 
quirements for topics. For example, the types of topics can be distinguished, such as single architectural design, planning or urban design, and thesis combined project topics, and all types of topics should be considered. In addition, for various types of topics, there must be clear requirements for the scale, difficulty, and workload of the task. Only when each topic selection can meet this standard, will there be no problems with large differences in topic selection difficulty, scale, etc., and ultimately, each student can be fully exercised through the graduation project. In addition, the selection of graduation project topics should also implement the principle of teaching students in accordance with their aptitude, so that all kinds of students can have greater room for improvement in the original design level and ability, and encourage some outstanding students to make innovations and breakthroughs (Xiao, Huang, \& Xu, 2016).

\subsection{The Diversity and Openness of the Topic Selection}

Diversified graduation project topics not only help mobilize the enthusiasm of students, but also meet the needs of students with different abilities and hobbies. Therefore, the topics of the architectural graduation project should be diversified. Under the guidance of the architectural professional theory teaching system and practical teaching system, combined with actual research projects and engineering, the requirements of the architectural function, space, shape, environment and other aspects should be fully integrated and established to develop multiple graduation project topics such as single building design, planning design or urban design combined with architectural design, design research (such as combined with site design, ecological design and Chinese ancient architecture design) and the topic of the thesis combined with the subject (preferably combined with architectural design) (Dai \& Zhang, 2019). Graduation project instructors can choose appropriate topics according to their own strengths and research directions, and at the same time, teachers should try to avoid repetition of topic types. The focus of the topic selection should not be limited to the single building design, but should also be combined with planning and design, protection and renewal, and teacher research and research topics, and take the road of diversified topic selection. At the same time, the creative thinking characteristics of architectural design determine that different people make different plans based on the same topic and the same conditions. Therefore, students of the same topic are encouraged to add "subtitles" by themselves, choose research directions and breakthroughs, and cultivate openness and creative thinking ability (Lan, 2008). In addition, the project topics must be appropriately updated every year, which can not only maintain the freshness of the students, but also avoid the plagiarism of repeated topics in the next session of students.

\subsection{The Authenticity and Feasibility of the Topic Selection}

Judging from the employment situation of our students in recent years, most of them are employed in small and medium-sized architectural design units and 
engaged in the design of a large number of ordinary civil construction projects. Therefore, the topic selection of the graduation project should be linked to the students' future work as much as possible, and some topics similar to the actual engineering project should be selected.

Generally speaking, the source of the topic selection of the graduation project can be divided into three types: fake questions and fake answers, real questions and real answers or real questions and fake answers. Fake questions and fake answers are designed by the instructor to design the subject, formulate the relevant design task book, and design the terrain virtually, which is similar to the usual architectural curriculum design. After all, there is a certain gap between the virtual subject and the real project, and the students are not very interested in it, so it's not suitable as a topic for graduation project; the real questions and real answers are often to choose the actual engineering project in the design institute for design. This method can not only improve the students' learning interest and practical ability, but also generate some economic and social benefits. However, it is not appropriate to use it as a graduation project; as the time required by Party A for the schematic design of actual engineering projects is generally tight, it is difficult to connect the design cycle with the graduation project; in addition, the actual engineering project will be constrained by many objective factors, such as cost factors, Party A's aesthetic taste, and government administrative department intervention, so students often fail to get comprehensive exercise (Ye, Han, \& Sun, 2013). The real questions and fake answers mean that the environment and requirements of the architectural design are real, and the basic materials such as topographic maps, planning opinions, and assignments are complete. Most of them are actual engineering projects familiar to the instructor or a real project of the design institute. According to the relevant materials, the instructor will make certain revisions to it in accordance with the requirements of the graduation project outline, and then use it as the student's graduation project topic to infect students with an atmosphere of "real combat", enhance students' interest in learning, make students familiar with the design process of actual engineering, gain more comprehensive practical experience and urge students to complete the process of transformation, maturity and transformation to the maximum extent before graduation (Feng \& Zhang, 2013). Judging from the actual teaching process of our school, this type of topic is a more appropriate source of topic selection in the graduation project, and it is more popular among students.

\subsection{The Adaptability and Uniqueness of the Topic Selection}

The topic selection includes the teacher's topic selection and the student's topic selection (while also choosing the instructor), which is a veritable "two-way choice". In order to achieve effective topic selection and avoid unnecessary work, the adaptability of topic selection must be fully considered, that is, the adaptability of both teachers and students to topic selection. On the one hand, when selecting topics, teachers should give full play to their own strengths and take into 
account the actual situation of the students; on the other hand, when choosing the instructor, students should fully consider whether the topic is in line with their interests, and whether the design task can be completed on time and with good quality, otherwise, the graduation project will not easily achieve the desired effect. Therefore, under the premise of ensuring normal teaching requirements, they must fully consider the adaptability of teachers and students to the topic.

When selecting specific topics, the method of "publishing topics-free choice-moderate adjustment" can be adopted to fully mobilize students' enthusiasm (Long \& Wu, 2011). First, the instructor introduces the background, concept, characteristics, content, key points and design requirements of the subject in charge; then students can choose freely according to their actual situation. After counting the number of topics selected in each group, appropriate adjustments are made according to the teacher-student ratio to finalize the graduation project group list. The topic selection must be different from person to person, make full use of strengths and avoid weaknesses; only in this way can we give full play to the initiative and creativity of teachers and students, so that the graduation project can receive the best results.

\section{Conclusion}

Taken together, the topic of the architectural graduation project should meet the teaching objectives, be diverse and authentic, but at the same time be appropriate in scale and moderate in difficulty. Graduation project is the last practical teaching link of undergraduate teaching in architecture. It is an important means to improve students' comprehensive quality. Appropriate topic selection of graduation project can not only enable students to get sufficient exercise, better complete graduation design, prepare for a smooth graduation, make a satisfactory appraisal for their five-year study process, and lay a good foundation for continuing to devote them to the construction industry in the future.

\section{Conflicts of Interest}

The author declares no conflicts of interest regarding the publication of this paper.

\section{References}

Dai, X., \& Zhang, H. (2019). Exploration of the Topic Selection for the Graduation Project of the Architecture Major from the Perspective of Yunnan Regional Culture. Journal of Higher Education, No. 8, 50-52+55.

Du, M. H., Zhang, J. F., \& Cheng, L. Z. (2011). Research on the Topic Selection of Graduation Project for Undergraduates in Engineering Colleges. China Adult Education, No. 11, 41-42.

Feng, L., \& Zhang, G. L. (2013). Analysis of the Problems and Countermeasures in the Topic Selection of the Graduation Project for the Engineering Major. China Electric Power Education, No. 16, 147-148.

Gui, W. Y., \& Wu, Y. F. (2020). Discussion on the Teaching Mode of Graduation Project 
for the Architecture Major in Local Colleges-Taking the Joint Graduation Project for the Architecture Major of Six National Architecture Schools as an Example. Journal of Higher Education, No. 10, 92-95.

Lan, G. (2008). Practical Exploration of Graduation Project Teaching for the Architecture Major. Shanxi Architecture, No. 2, 230-231.

Liang, X. C., Xuan, W. H., \& Li, H. (2009). Research on the Process Control Strategy of Graduation Project for the Applied Architecture Major. Journal of Architectural Education in Institutions of Higher Learning, 18, 100-103.

Long, W. R., \& Wu, G. Z. (2011). Discussion on the Quality Control System of the Whole Process of the Graduation Project Teaching for the Architecture Major. Theory and Practice of Contemporary Education, No. 12, 100-102.

Nie, H. D. (2008). Brief Introduction to the Process Teaching of Architectural Graduation Project. Proceedings of the 2008 National Conference on Architectural Education, 295-298.

Su, Y., Liu, P., \& Pan, P. (2011). Research on Topic Selection of Graduation Project for the Civil Engineering Major. Science \& Technology Information, No. 21, 180-181.

Xiao, D. W., Huang, Y., \& Xu, J. H. (2016). Thoughts on the Teaching of Architectural Graduation Project. Huazhong Architecture, No. 5, 135-138.

Ye, C. L., Han, X. M., \& Sun, M. L. (2013). Some Thoughts on the Topic Selection of the Graduation Project. Education and Teaching Forum, No. 51, 89-90.

Zhang, S. R., \& Song, X. Q. (2011). Some Thoughts on the Teaching of Graduation Project for the Architecture Major. China Electric Power Education, No. 29. 